\title{
Challenges and Prospects of Local Development Plan Implementation in Dire Dawa: The Case of Kezira City Center
}

\author{
Zewdu Teshome \\ Dire Dawa Management and Kaizen Institute, Dire Dawa, Ethiopia
}

\begin{abstract}
In the history of Ethiopian urban development, planned urban development is a recent phenomenon especially in Dire Dawa. In the past, many endeavors were made to guide the development of Dire Dawa in a planned manner. For instance, Kezira is the first urban center in Ethiopia developed with a proper plan since the beginning of the 'Gezira' plan of 1909. Recently, various local development plans have been developed as a means to realize the structure plan of the city. However, so far no study has been conducted that critically analyzes the implementation challenges of the Local Development Plans in Dire Dawa. The purpose of this study is therefore to assess the administrative challenges and prospects in the implementation of Kezira Local Development Plan (LDP) in Dire Dawa City. To this effect, three research questions were employed to guide the study. These were: 1) what are the major factors that necessitate LDP in the city; 2) what are the administrative challenges hindering the implementation of Kezira LDP; and 3) what are the major prospects in the realization of LDPs in the city? Moreover, two data gathering techniques: simple random sampling and purposive sampling were used to obtain relevant data required for the study. In the primary data gathering technique, questionnaire that were designed and distributed to Kezira residents were used. For further elaboration, interviews were conducted with selected officials and experts from Dire Dawa Land Development and Management Bureau. Secondary data from different sources were employed. The data gathered from both primary and secondary sources were analyzed using descriptive and statistical methods such as percentages, tables, charts, and photos. The results of the study indicated that factors like centrality, strategic, and comparative and competitive advantages of the study area necessitated LDP intervention. Lack of adequate and experienced professional staff, poor documentation of plan implementation records, shortage of budget, lack of commitment of management and lack of political attention for public concerns, proliferation of rent seeking attitudes, lack of operational manuals and procedures, and the existence of significant number of bi-national properties (belonging to Ethiopia and Djibouti) such as housings in the study area were major challenges encountered in Kezira LDP implementation. The major prospects for the implementation of LDP in the city were the redevelopment, and other policy and regulatory interventions being made by the Federal and the City Administration of Dire Dawa. Finally, based on the analysis and conclusions, possible recommendations were suggested for alleviating the major challenges of LDP implementation in the study area. Thus, it is recommended that the Land Development Management Bureau should work in collaboration with the community and other relevant stakeholders and exert all possible efforts to mitigate the challenges and thereby enhance the performance of LDP projects in the city in general.
\end{abstract}

Keywords: Urban Development, Kezira, Local Development Plan.

DOI: $10.7176 / C E R / 12-2-03$

Publication date: February $29^{\text {th }} 2020$

\section{Introduction}

Urban planning, as one of the most important tools of urban management, guides the socio-economic and physical development of an urban area (MWUD, 2006). In other words, it is an activity carried out in a planning center to meet the socio-economic and spatial development needs of a given urban population. Thus, without the guidance of urban planning no development effort can be realized in an urban center. According to the "Urban Planning Proclamation No. 574/2008", urban plans are recognized as City-Wide Structure Plan and Local Development Plan (LDP). LDP is a local level urban plan, which is prepared within the framework of a structure plan. It is a detailed plan that focuses on specific locality of an urban center for immediate implementation, and thus is a tool for implementation of structure plan proposals (MWUD, 2006).

Most of Ethiopian cities and towns are predominantly unplanned. The prevalence of unplanned development in Ethiopian urbanization in turn poses a substantial need for re-planning of urban centers in the country. The replanning involves an extensive land-use readjustment, fundamental reorganization of infrastructure networks as well as revitalizing dilapidated urban fabrics. In this regard, LDPs play significant roles (MWUD, 2006). Nowadays, the government of Ethiopia is providing support for the preparation and implementation of urban plans for urban centers. Actually, all of the urban areas need plans to guide their developments; yet LDPs are limited to few urban centers (Ibid). Many urban development proposals, particularly LDPs, apart from providing urban centers with opportunities for the implementation of urban planning policies at local level, they are supposed to improve the social, economic and physical developments of cities and towns. Yet this is not the case in few urban centers of Ethiopia. For example, the case study on the Senga Tera-Fird Bet I redevelopment project by Ezana H. 
(2011) pointed out that the major emphasis of the project was for beautification of the area. According to the above document, the project was viewed as less uniform in terms of its coverage, less responsive, less efficient in use of resources, less effective in achieving its objective and less sustainable by some sections of the affected group that indicates less effectiveness of the participation process (Ibid). In support of the above idea, Dejene M. (2005) found out that financial, institutional and legal problems were the major problems that hindered the implementation of LDPs in Addis Ababa.

DDA is one of the biggest cities in Ethiopia and it shares the above mentioned problems in its urban redevelopment implementation process. The City Administration has a number of problems related to LDPs implementation. Currently, the City Administration has conducted about 17 LDP studies of which the Kezira LDP is the first one, and is meant to solve linkage problem due to Dechatu River and railway station, inefficient and incompatible land uses, and lack of recreational places, congestion and other socio-economic problems such as unemployment, etc (Wondimu Consult, 2008). Evidences of the five year (2003 E.C - 2007 E.C) report document of the Land Development and Management Bureau indicated that the office had planned to lower down the proportion of dilapidated and deteriorated condition of cities from $45 \%$ to $30 \%$ through the development of 3.56 hectares of urban land in Kezira, Megala, and Sabian LDP sites. However, the performance of the city's LDPs implementation was not satisfactory. Therefore, the poor performance of LDPs implementation, if ignored, can be a threat to the achievement of the City's urban re/development objectives. As to the researcher's knowledge there is no available documented case study on the assessment of challenges and prospects in implementation of LDPs in Dire Dawa. Hence, the researcher has intended to go through the study, to fill the gap in this regard, and to assess the administrative challenges and prospects in implementation of Kezira LDP in Dire Dawa.

\subsection{Basic Research Questions}

1. What are the major factors that necessitate LDPs in Dire Dawa?

2. What are the administrative challenges hindering the implementation of Kezira LDP in Dire Dawa?

3. What are the major prospects in the realization of LDPs in Dire Dawa?

\subsection{Objectives of the Study}

The general objective of the study is to assess the administrative challenges and prospects in implementation of Kezira LDP in Dire Dawa.

\subsubsection{Specific Objectives of the Study}

The study also tries to achieve the following specific objectives:

1. To describe the major causes that call for the need for LDPs.

2. To identify the administrative (financial, institutional, political and legal) challenges those hinder the implementation of Kezira LDP.

3. To find out prospects in the realization of LDPs.

4. To forward possible recommendations/solutions to improve the implementation of LDPs.

\subsection{The study area description}

The study area is Kezira, which is found in kebele 03 of Dire Dawa and is located at the center of the city, as seen in the figure below.

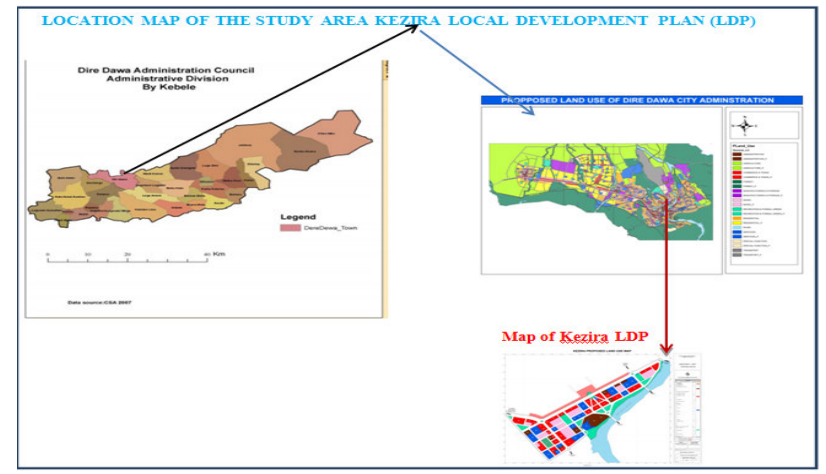

Source: Compiled by the author from different maps, 2015

\section{Challenges and Constraints of LDP implementation}

Urban areas in any nation are often working under pressure of constant change. When the socio-economic structures of an urban center continuously change over time, the spatial frameworks of the urban utilities are also undergoing the same change. Urbanization can be expressed as the physical growth of urban areas and its population due to natural increase and migration. The rapid growth of population together with lack of capacity to accommodate the people will lead to high concentration of population in cities or towns with insufficient infrastructure and services. This has resulted in the creation of polluted environment, slum formation, proliferation 
of squatter settlements and poverty. It is said that planning is not without failure; and failure usually stems from problems. According to Yohannes (2012), the problems of urban planning could be lack of sufficient resources and attention, lack of civic participation, absence of information, action or community support. Likewise, Ashenafi (2001) found out that the practice of inner city renewal had several weaknesses of which the major ones were: lack of community participation, lack of well-defined improvement policies and lack of coordination and lack of concern for socio-economic issues. Similarly, Dejene (2005) tried to summarize problems that are related to LDP implementation in Addis Ababa City Administration as follows:

Unsuccessful and Poor Integration: this relates to the lack of coordination between different infrastructure institutions that involve in land development. The fact that land development was not the single most priority of the infrastructure institutions resulted in poor integration of the institutions and thereby hampered implementation of LDPs. It was also noted that the problem of staffing of the institutions contributed a lot for the inefficiency of the institutions.

Lack of Strategic Focus, Prioritization and Action was also another reason for the unsuccessful implementation of LDPs in Addis Ababa. The local development agency of Addis Ababa aspired to implement LDPs with a limited capital budget much less than the required amount, in a period of one year without proper staffing, led again to the unsuccessful implementation of the LDPs. Lack of focus and prioritization was also observed at city level. The City Government in its ambitious plans was also involved to solve every visible problem of the city, from the micro and small businesses to a huge inner-city renewal program, without an honest evaluation of its capacity. Due to this the problems of LDP implementation was given secondary importance.

Lack of Clear Regulations also affected implementation of LDPs negatively. As confirmed by the authorities of Addis Ababa local development agency, the compensation policy and system was outdated and unclear. The cost estimates of the houses in the city were done long time ago and the prices of the houses found in the city's archive were outdated and much below today's housing market prices. Hence, this created a lot of inconvenience on the part of property owners and on the operations of the agency, which necessitated adapting new compensation policy and system in the city.

Unclear Institutional Hierarchy also created an obstacle in the performance of LDP executing agency. The working relationships between different institutions that deal with the issues of land and planning were not clearly defined.

Changing Policies also caused a number of problems with respect to LDP implementation. LDPs are usually prepared by considering certain assumptions, of these assumptions do not persist the LDPs should either be discarded or revised. For instance 'Meri Luke' LDP was prepared for housing purpose to be executed on the basis of individual plots but in the middle of implementation condominium policy was introduced and its implementation had to discontinue.

Unclear Regulations and Lack of Appropriate Tools to implement the policies and the assumptions of the LDP were the major challenges that implementers faced.

\subsection{Research Design}

The study employed descriptive research design to identify and describe the challenges and prospects of LDP implementation. The research approaches that were adopted by this study are both quantitative and qualitative. The quantitative approach helps the researcher to study the issue in breadth while the qualitative approach helps to study attitude, opinions in depth. Hence, the quantitative methods involve the use of household survey whereas the qualitative methods include key informant interview and field observation.

\subsection{Methods of Data Collection}

Both primary and secondary data were collected by employing quantitative and qualitative methods. Purposive sampling technique was employed to select municipality head, land development and management head, plan preparation and information core process owners, kebele 03 leaders and experts. Interviews were used to obtain the required data from employees and officials. Questionnaires were designed for those sample households who are currently residing in the Kezira LDP area.

\subsection{Sampling Technique and Sample Size}

The target population of the study is the entire households at the Kezira LDP site of Kebele 03 in Dire Dawa. According to the Local Development Plan document of Kezira, the total number of households in the planning site is 686. According to Kothari, C.R. (2004), the formula below is used to calculate the sample size as:

$$
\begin{aligned}
& \mathbf{n}=\frac{\mathbf{z}^{2} \mathbf{p q} \mathbf{N}}{\mathrm{e}} \\
& \mathbf{e}^{2}(\mathbf{N}-1)+\left[\mathbf{z}^{2} \mathbf{p q}\right] \quad \text { (Kothari, C.R., 2004) }
\end{aligned}
$$

Where:

$\mathbf{n}$ : is the sample size for a finite population

$\mathbf{N}$ : size of population which is the number of households 
p: population reliability/frequency estimated for a sample of size $n$, where $\mathbf{p}$ is 0.5 and $\mathbf{p}+\mathbf{q}=\mathbf{1}$

e: margin of error considered is $10 \%$ for this study.

$\mathbf{Z}_{\mathbf{\alpha} / 2}$ : normal reduced variable at 0.05 level of significance $\mathrm{z}$ is 1.96 .

$\mathrm{n}=\frac{(1.96)^{2} \times 0.5 \times 0.5 \times 686}{(0.1)^{2}(686-1)+[(1.96) \times 0.5 \times 0.5]}=84$

According to the above formula, the sample size for this study is $\underline{84}$ households.

\subsection{Method of Data Analysis and Interpretation}

The information collected from both primary and secondary data sources through review of different documents, interviews with informants, and questionnaire survey were organized and narrated. To be specific, respondents' opinion on the questionnaire survey were summed up by frequency counts and then converted into percentages using Statistical Package for Social Scientists (SPSS) software to analyze the quantitative data numerically. Likewise, qualitative data generated from informant interview, and secondary sources were analyzed by content analysis.

\section{Conclusion}

It is believed that urban planning in Ethiopia is an essential element that is intended to regulate and guide the proliferation of unplanned urban centers to bring about balanced and integrated national, regional and local development. As major planning instruments, the City Administration of Dire Dawa has developed the Structure Plan and the Local Development Plan (LDP) to guide the development of the city. LDPs are planning tools through which the implementation of the provisions of the Structure Plan can be realized. These plans are certainly believed to provide feasible development directions to some strategic investment areas or intervention sites already identified in the structure plan of the city.

\section{Factors that Necessitate the Initiation of the Local Development Plan in Dire Dawa}

Kezira, being the foundation and center of the city, was one of the strategic intervention areas as identified by the structure plan, for which the existing LDP study was prepared. On the other hand, the area was selected as a redevelopment intervention area for the reasons that it has been underdeveloped, calm and economically less active with time, and unattractive. Moreover, the study area lacked connectivity and blocked by the railway station and the long fence of the railway; most of the buildings were attached and single storey which were built long years ago and presently are obsolete requiring redevelopment; and majority of the housing units were in poor condition; and these were other factors that call for LDP intervention in the study area. On top of these, the result of field survey showed that the majority of the housing units in the study area were government owned public rental housing; and the area was relatively good location for commerce and service where agglomeration of these functions were found, for which the city administration gave main concern to redevelopment intervention to take advantage of the centrality and strategic development opportunities of the area. Therefore, the centrality, strategic, and other competitive advantages of the study area were major factors that stimulated the city administration to take redevelopment intervention.

\section{Major Challenges of Kezira Local Development Plan Implementation}

The results of the survey and the interviews made with informants in the analysis part revealed that the implementation of kezira LDP had encountered a number of challenges. Some of the major challenges that the LDBUR and City Plan and Data Preparation (CPDP) core processes which had significant roles in facilitating the preparation and implementation of the LDP plan were lacking more than half of the total professionals required for them in accordance with their respective business process reengineering (BPR) study documents (See Table 4.5); and shortage of experienced professionals. This lack of adequate and experienced professional staff was significantly affecting the implementation of the LDPs in the study area as well as in the city. The annual allocated budget of the LDP project was not adequate to ensure complete accomplishment of the project objectives. The office's capital budget performance was also very low.

As far as the political and legal challenges were concerned, the officials were not committed and gave little attention to the LDP project of the study area. There were also poor documentation of plan implementation documents, lack of commitment of management; proliferation of rent seeking attitudes; and lack of political attention for public concerns and unavailability of mechanisms in place to ensure the demands of residents in the development and implementation of the LDP in the study area. In addition to this, the LDP study documents already prepared were lacking manuals and procedures for their enforcements and realization. The existence of railway station owned houses in the study area is also one challenge that significantly affects the implementation of the Kezira LDP. The result of interviews made with the LDBUR core process indicated that the bi-national ownership nature of the area makes the implementation of the LDP a difficult situation.

Major Prospects of Local Development Plan (LDP) in Dire Dawa City

Dire Dawa City Administration has given priority for the city's redevelopment program. Currently, the City 
Administration has prepared some 17 LDP studies. The ones previously studied were Kezira LDP (2008) and Megala LDP (2010). The city and the already studied LDP sites have competitive and comparative advantages of relatively good location, accessibility of services, commerce, and infrastructure, expansion of industries, warehouses and the ongoing national railway development, which are development potentials of the city administration that will provide good opportunities for the implementation of the LDP projects.

On the other hand, the existence of various policies and legal frameworks which were established at Federal government and City Administration level to deal with the issue of urban redevelopment programs were also other prospects for the implementation of LDP projects in the study area and in the city. Some of the major ones were National Development Policy, Growth and Transformation Plan, Urban Planning Proclamation, Land Development and Management Policy, and Proclamation No. 455/2005 and Regulation No. 135/2007 (legal documents for redevelopment and compensation matters); and those established by Dire Dawa Administration were the Administration's Growth and Transformation Plan (2010/11-2014/15), Urban Land Lease Holding Regulation No. 8/2013, and Directive Number 9/2014. All these policy and regulatory frameworks can be considered as major prospects for the realization of urban redevelopment objectives in the city administration.

\section{Recommendations}

This section provides the suggested recommendations to be taken as measures to mitigate challenges persisting in the implementation of Kezira LDP in particular and other LDPs in general. According to the main findings of the study, the implementation of Kezira LDP has encountered the following major challenges such as lack of adequate and experienced professional staff, poor documentation of plan implementation records, shortage of budget, lack of commitment of management and lack of political attention for public concerns, proliferation of rent seeking attitudes, lack of operational manuals and procedures, and the existence of significant number of bi-national properties (belonging to Ethiopia and Djibouti) such as housings in the study area. Depending on the main findings and conclusions, the writer of this thesis would strongly like to recommend the following possible recommendations to mitigate the aforementioned challenges:

* To alleviate the prevailing inadequacy of skilled and experienced manpower, the Land Development and Management Bureau should design mechanisms both to attract skilled and experienced professionals from outside and to develop the existing staff through a continuous human resource development program.

* Documents prepared during plan development and implementation process such as periodic reports of plan implementation, and other relevant documents need to be available in the office in such a way that they should be organized both in hard and soft copies.

* The City Administration and Land Development and Management Bureau should expand financial resources by introducing different fund raising programs; by mobilizing resources from the existing potential residents of LDP sites by giving them priority to invest in the same location; and by attracting investment from private sectors and Non Governmental Organizations for the implementation of the local development plan in the study area. The Land Development and Management Bureau also need to improve the performance of its allocated budget through a continuous periodic review and monitoring.

* The Land Development and Management Bureau need to develop a strategy that guides the various consultation forums to ensure active participation of residents and other relevant stakeholders in every stages of the redevelopment process starting from the initiation of the LDP projects, and that helps build the capacity of management/officials and relevant decision makers to have a clear vision of implementation and take part to play their role and responsibilities in the implementation of the projects.

* The Land Development and Management Bureau need to give prior attention for the preparation of relevant procedure and manuals to facilitate the implementation of local development plans in the city.

* The existence of significant number of bi-national properties (belonging to Ethiopia and Djibouti) such as housings in the study area is a major challenge that significantly affects the implementation of the Kezira LDP. Therefore, negotiation between the two countries might be required and appropriate implementation strategies should be devised to mitigate the challenge.

\section{References}

Ashenafi Gossaye, (2001) Inner-City Renewal in Addis Ababa: The Impact of Resettlement on the SocioEconomic and Housing Situation of Low Income Residents. NTNU, Trondheim, Norway.

Central Statistical Agency of Ethiopia, (2008). Summary and Statistical Report of the 2007 Population and Housing Survey. CSA: Addis Ababa.

Chris C., (1990). Urban Renewal Theory and Practice, London: Macmillan Education Ltd.

Davidson, F., (1996). Planning for performance: Requirements for sustainable development. Habitat International. Dejene M., (2005). Implementation of Local Development Plans in Addis Ababa: the case of ECA LDP. Master of Science in Urban Design and Planning edn. Addis Ababa: Addis Ababa University.

Development Partners, (2014). Urban Design of Kezira and Megala Dire Dawa City. Land Development and Management Bureau, Dire Dawa, Ethiopia. 
Ezana H., (2011). Factors Influencing Affected Group Participation in Urban Redevelopment in Addis Ababa: The Case of Senga Tera-Lideta Project. Masters of Sceince in Urban Management and Development edn. Institute of Housing and Urban Development Studies (IHS). Rotterdam: Erasmus University Rotterdam.

F.D.R.E., (2004). Dire Dawa Administration Charter Proclamation No. 416/2004. Ethiopia: Addis Ababa.

F.D.R.E., (2008). Urban Planning Proclamation No. 574/2004. Ethiopia: Addis Ababa.

F.U.P.I., (2006). Integrated Development Plan (IDP) of Dire Dawa Administration.

Federal Democratic Republic of Ethiopia Ministry of Finance and Economic Development (2010). Growth and Transformation Plan, Addis Ababa, Ethiopia

Hiraskar, G.K., (1998). An Introduction to the Fundamentals of Urban Planning (M. Salmani and A. Reza Yekani Trans.), Tehran: University for Teacher Education.

Kothari, C.R., (2004). Research Methodology: Methods and Techniques, New Delhi: New Age International (P) Ltd, (2 $2^{\text {nd }}$ ed. $)$.

LDMB (2015). The five year (2003 E.C - 2007 E.C) report of the Land Development and Management Bureau, Unpublished. Dire Dawa, Ethiopia.

Ministry of Works and Urban Development. (2006). Manual for Local Development Plans. Addis Ababa: Ethiopia Birhanina Selam.

Ministry of Works and Urban Development. (2012). Structure Plan Manual (revised version). Addis Ababa, Ethiopia.

Prasad D.R., (1989). Urban Renewal: the Indian Experience. India: New Delhi.

UN-Habitat (2008). Dire Dawa Urban Sector Profile Study. Kenya: Nairobi.

Water Works Design and Supervision Enterprise (WWDSE), (2005). Dire Dawa Integrated Natural Resource Master Plan Study. Dire Dawa, Ethiopia.

Wondimu Consult, (2008). Kezira Local Development Plan (LDP) Final Report.

Yohannes D., (2012). Assessment of Urban Plan and Design Implementation and Management in Ethiopian Secondary Towns: The Case of Dilla. Master of Science Degree in Urban Design and Development. Addis Ababa: Addis Ababa University. 